\title{
Seguint els passos de Sant Vicent Ferrer al Regne de Nàpols i Sicília
}

\author{
[On the trail of San Vicent Ferrer \\ in what was the Kingdom of Naples and Sicily]
}

\author{
Anna Maria Compagna \\ Università degli studi di Napoli Federico II \\ compagna@unina.it
}

\begin{abstract}
Resum: Al present article es proposa fer una ullada a alguns elements que permeten afirmar que el culte al sant, al sud d'Itàlia, és viu i es pot veure a partir de diferents textos, pintures en esglésies i festes, tot començant per la Summa dei re di Napoli e Sicilia e dei re d'Aragona, text hisoriogràfic del valencià Llop de Espejo, copiat a Nàpols el 1468. El que llegim a la Summa, a propòsit de la canonització del sant el 1455, ens permet veure que aquella data va ser el primer moment en què la presència del frare ja difunt es va fer notar de forma potent, no sols entre els valencians, sinó també entre tots els súbdits del regne de Nàpols. Malgrat que entre el 1406 i el 1407 no siga fàcil saber on va estar el sant, no sembla que haja pasat pel sud ni pel cenre d'Itàlia. Amb tot, si es mira l'elenc de les obres d'art que representen al sant a l'àrea italiana, es veurà que les localitats on es poden veure es troben distribuïdes de manera equànime per tot el territori italià i tenen unes motivacions anàlogues. No és certa la creença que el culte al sant siga més intens al sud.
\end{abstract}

Paraules Clau: Sant Vicent Ferrer, Regne de Nàpols i Sicília, folklore, Llop de Espejo, Lupo de Spechio

AвsтRAct: We propose some pieces that make it possible to affirm that the Saint's cult in the South of Italy is alive and continues throughout the centuries in various types of texts, in paintings, in churches and in related festivals, starting with Summa dei re di Napoli e Sicilia e dei red'Aragona, historiographic text of the Valenzano Lupo de Spechio (Naples, 1468). Now what we read in Summa, about the canonization of the Saint in 1455, allows us to state the date of the event was the first moment in which the presence of the now defunct friar had to be noticed in a striking way not only among the Valencians, but also among the subjects of the Kingdom of Naples. And even if between 1406 and 1407 it is difficult to follow the Saint on his apostolic journeys, he does not seem to have passed either to the South, or to Central Italy. Yet, if you look at the list of works of art depicting the Saint in the Italian area, you will see that the locations where they are located are equally distributed throughout Italy and have more or less similar motivations. So it is not true that what is commonly believed is that in Italy the cult of the Saint is particularly felt in the South.

KEYwords: Saint Vincent Ferrer, Kingdom of Naples and Sicily, folklor, Llop de Espejo, Lupo de Spechio

Recepció: 26/02/2019. Acceptació: 08/03/2019. Publicació: 05/04/2019

REVISTA VALENCIANA DE FILOLOGIA/I I I (20I9) p. I27-I38/ISSN 0556-705X/DOI I0.28939/RVF.V3IO.62 


\section{La Summa de Lupo de Spechio i La vida y historia (València 1575) traduïda del castellà a l'italià (Palerm 1600).}

Seguir els passos de sant Vicent Ferrer al regne de Nàpols i Sicília demana tenir en compte, també, allò que ocorre a la resta d'Itàlia, i — ho avance jatrobarem que la situació en terres meridionals tampoc es veu privilegiada, com es podria pensar: al sud d'Itàlia no hi ha cap primacia, respecte a la resta de territoris italians, i que a més a més seria ben poc significativa. I menys, després d'escoltar la magnífica intervenció de Chiara Concina sobre la presència del sant al nord d'Itàlia. No és per casualitat que aquest congrés dedica dues ponències a la presència del sant en aquella zona i només una al que va ser el regne de Nàpols i Sicília. Tot açò, i més, és allò que presentaré ara, després de la investigació que he realitzat i que presente en aquest congrés dedicat a commemorar els 600 anys de la mort del sant. Vull aprofitar, també, aquest moment, per a agrair de cor als organitzadors per haver-me invitat a participar en aquesta trobada.

Si eixim del que va ser el regne de Nàpols i Sicília, com deia, la fama i la devoció a Vicent Ferrer no canvien. El culte del predicador dominicà, «venerato come santo già durante la vita, si diffuse rapidamente attraverso parole e immagini dopo la sua canonizzazione» (Živkovic 2017: 47).

Però anem per parts: comencem pel regne de Nàpols i Sicília i un text historiogràfic del qual he realitzat l'edició crítica (Compagna, 1990). El manuscrit fou «copiato in Napuli a dì del mese de magio, anno domini nostri Ihesu Christi 1468» (Compagna, 1990: 68).

Dos són els capítols que Lupo de Spechio consagra a sant Vicent Ferrer en la segona part de la seua Summa dei re di Napoli e Sicilia e dei re d'Aragona, aquella que es dedica a «como descendeno li ri de Aragona fini al'anno 1468». Podeu veure'ls a l'Apèndix I d'aquest article (Compagna, 1990: 134-135).

Escartí (2018: 305-309) escriu que la importància del sant degué manifestar-se de manera patent entre els valencians, ja l'any 1455, a partir de la seua canonització. Es tracta del primer personatge local que va assolir tanta importància i per això es comprén molt bé el fervor popular que en va derivar

REVISTA VALENCIANA DE FILOLOGIA / III (20I9) p. I27-I38

ANNA MARIA COMPAGNA

Seguint els passos de Sant Vicent Ferrer al Regne de Nàpols i Sicília / I 28 
i que portà a l'organització de festes i processons, com testimonia la Crònica $i$ dietari del capellà d'Alfons el Magnànim (Miralles, 2011).

Ara bé, allò que es llegeix en la Summa, al voltant de la canonització del sant, ens permet afirmar que l'any 1455, data de l'esdeveniment, va ser el primer instant en què la presència del frare, aleshores ja difunt, es degué notar de manera evident no solament entre els valencians, sinó també entre els súbdits del regne de Nàpols. I, probablement, també allà on Vicent Ferrer havia dut la seua paraula, ${ }^{1}$ amb la seua parla particular, de la qual ara se cerca debades una conprovació directa impossible, i de la qual hem de conformar-nos amb una d'indirecta.

Respecte al regne de Nàpols i Sicília, després de la Summa de Lupo, cal destacar el fet que La vida y historia, publicada per Pedro de Hueste, el 1575 a València, va ser traduïda del castellà a l'italià en l'edició de Giovanni Antonio de Franceschi, a Palerm en 1600.

En transcric el frontispici ací:

La Vita et Historia dell'Apostolico Predicatore S. Vincentio Ferrer Valentiano dell'ordine di S. Domenico. Raccolta dal molto R.P. Maestro Fra Vincentio Iustiniano Antist. in quel tempo Lettore di Theologie nella Università di Lucente dell'istesso Ordine, et Provincia.

Di nuovo tradotta da spagnola in lingua italiana, per il P. Fra Iacopo

Magdalena Lettore Siciliano di Palermo dell'istesso Ordine de

Predicatori.

Al molto Ill. Sig. Bernardo Delyermo del Conseglio de sua Mae tà, e suo Thesorero generale è deputato in questo fedelissimo Regno, Capitano et Iustitiario in questa Felice Città di Palermo.

In Palermo

Per Gio. Antonio de Franceschi, M. DC. ${ }^{2}$

1 De fet, Calixt III va declarar la santedat de sant Vicent Ferrer en un consistori públic, «dopo aver sottoposto a un rigoroso esame i dati raccolti principalmente dagli emissari di Bretagna» (Compagna, 1990: 174).

2 Ací i més endavant, propose una transcripció paleogràfica i no interpretativa.

REVISTA VALENCIANA DE FILOLOGIA / I I I (20I9) p. I27-I 38

ANNA MARIA COMPAGNA

Seguint els passos de Sant Vicent Ferrer al Regne de Nàpols i Sicília / I 29 
Especialment significativa semblaria la comparació del text italià amb el castellà, per a poder llançar nova llum sobre el que degué ser la presència del sant a Itàlia, potser justament a partir del regne de Nàpols i Sicília. Les traces d'aquesta presència han aparegut ací i allà, començant per l'àrea napolitana, però no sols ací, com tractarem de demostrar. Es tracta de petjades que se situen en aquella xarxa coherent, a la qual Ferrando va dedicar un llibre seu (Ferrando 2013).

Vegem-ne la primera pàgina de l'índex de la traducció italiana, al costat del text castellà. La mera comparació ens dirà alguna cosa.

«La lettera Viceregia», l' «Epistola che fa l'Authore à cui e concessa questa opera», l'«Epistola alli Lettor.» i el «Prologo, et argumento dell'opera al Cristiano lettore» substitueixen la "Carta dirigida a los señores Iurados desta ciudad, que començaron su officio a Pentecostes del año 1574», que trobem en el text castellà.

Segueixen les rúbriques dels primers capítols: Així, el «Cap.I. Della sua Nativita fanciullezza, e gioventù dello detto Santo» tradueix el "Capitulo.I. Del nacimiento, y niñez: y mocedad de san Vicente»; a continuació el «Cap.2. Come S. Vinc entrò nella Religione, e della vita che in quella fece infino che fu fatto Maestro in Theologia» correspon al "Capitulo.2. como entro en la religion de los frayles predicadores, y de la vida que en ella hizo hasta que tomo el grado de maestro en Lerida.». Després, el «Cap.3. come ritornò il detto $S$. Vincen. a Lerida et a Valentia, e delli lazzi, et impredimenti, che il Demonio li diede per le mani» tradueix el «Capitulo .3. como boluio de Lerida a Valencia, y de las acechanzas del demonio que en ella padecio». I així, semblantment.

Com es veu, la traducció italiana ofereix una mena d'actualització de l'original castellà sobre la qual paga la pena reflexionar, si més no, per a assenyalar que cada traducció és una forma de reescriptura del text que s'està traduint, una manera de contextualitzar l'obra traduïda en el temps i l'espai, diversos d'aquells de l'original, per a adaptar el text nou al públic al qual va dirigit, que al seu torn pot no ser el mateix. En el nostre cas, semblaria que la circulació del text italià preveia un públic menys laic, $i$, per tant, que es tractara d'una circulació en àmbits més clericals.

REVISTA VALENCIANA DE FILOLOGIA / III (20I9) p. I27-I 38

ANNA MARIA COMPAGNA

Seguint els passos de Sant Vicent Ferrer al Regne de Nàpols i Sicília / I 30 


\section{En la cultura regional de Campània}

Tornant a la recerca de les traces de sant Vicent al regne de Nàpols i Sicília, es pot dir que els indicis d'aquest interés pel sant a Itàlia han aflorat ací i allà, sobretot en l'època aragonesa. Penseu en les arts figuratives: ben conegut és el políptic de Colantonio, del 1460, en l'església napolitana de Sant Pere Màrtir, ara al Museu de Capodimonte de Nàpols, en la sala $67,{ }^{3}$ que és fins i tot anterior al testimoni de Lupo. En les manifestacions iconogràfiques s'expressen plenament «le modalità generali di diffusione del culto del nuovo santo» (Živkovic, 2017: 43).

En tot cas, si continuem seguint les traces d'aquest interés, sembla que se separa de la dependència dels textos castellans, com es veu en el cas de la traducció publicada a Palerm en 1600, ja esmentada, i es troben algunes vides del sant, entre les quals també aquella que es pot llegir dins el Sacro Diario Domenicano di Domenico Maria Marchese (Nàpols, Geronimo Fasulo, 1669), ${ }_{4}$ i el tractat qeu porta per títol Vita, e miracoli dell'Apostolo Valenziano San Vincenzo Ferreri dell'Ordine de' Predicatori, del valencià Vicent Vitòria (Roma, Zenobi, 1705). ${ }^{5}$ Aquest últim era un pintor que es va formar a Roma al costat de Carlo Maratti i la seua producció artística es desenvolupà entre Roma i València; no és l'únic valencià que es movia amb desimboltura per Roma, centre artístic per excel-lència del seu temps, una experiència que li feu guanyar el títol d'antiquario del papa Climent XI i de pintor oficial del gran duc de Toscana (Alcahalí, 1897: 327-330).

La fama del sant, trasplantada a Itàlia, continua en l'època virregnal, i en la Roma papal amplia la seua presència a través de l'art i les lletres.

3 Podeu veure'l a <https://it.wikipedia.org/wiki/Catalogo_dei_dipinti_del_Museo_nazionale_di_ Capodimonte>

4 Accessible a <https://books.google.it/books?id=5rNTaytlehkC\&pg=PA137\&lpg=PA137\&dq=Domenico+Maria+Marchese+ferrer\&-source=bl\&ots=nrySOfeSov\&sig=WTDjih_3srmOqXIq8RQU7YJuymI\&hl=it\&sa=X\&ved=2ahUKEwievqC8h6HeAhUKVhoKHeCQAOgQ6AEwAXoECAgQAQ\#$\mathrm{v}=$ onepage $\& \mathrm{q}=\mathrm{e} \% 20$ ferrer $\& \mathrm{f}=\mathrm{false} .>$

5 Accessible a <https://reader.digitale-sammlungen.de/de/fs1/object/display/bsb10789084_00005.html.>

REVISTA VALENCIANA DE FILOLOGIA / I I I (20I9) p. I27-I38

ANNA MARIA COMPAGNA

Seguint els passos de Sant Vicent Ferrer al Regne de Nàpols i Sicília / I 3 I 
Aquestes dades ens porten a aprofundir en aquella xarxa que emergeix de les diverses manifestacions artístiques i textuals ja esmentades, amb la finalitat de donar-los la necessària coherència per a poder dibuixar el recorregut de la presència del personatge i, també, d'una certa naturalització de sant Vicent a Itàlia, reconeixent els lligams sincrònics i diacrònics —a banda d'aquells que podríem anomenar, per simpatia, sintagmàtics i paradigmàtics- d'allò conegut, amb les integracions possibles corresponents.

I en l'ordit d'allò conegut no s'entrellacen només els fils de l'escrit. La cultura escrita s'incardina amb la tradició oral, que aflora també gràcies a les construccions artístiques, a les esglésies, per exemple, que no sempre són monuments, però sí documents de la vida quotidiana del passat i del present. Escartí (2018) escriu que la imatge mítica d'aquell sant taumaturg, gràcies, en part, als hagiògrafs antics, no ha tingut cap dificultat per a guanyar-se un lloc de relleu en l'imaginari col-lectiu no sols del poble valencià, sinó també en aquells d'altres països on es parla la llengua del sant —els pares del qual eren gironins-, i, encaara, en els territoris de Nàpols, Sicília, Bretanya o Múrcia.

I, de fet, la cultura popular diu que:

il suo culto si è diffuso nei secoli in tutta l'Europa ed oltre, manifestando vette di massima devozione negli Stati che hanno conosciuto un contatto diretto con la cultura spagnola e con l'Ordine dei Domenicani come l'America Latina, nel dettaglio in Venezuela, Brasile, Cile e Colombia mentre in Italia il suo culto è particolarmente sentito nel Sud dello Stivale. ${ }^{6}$

A hores d'ara aquest culte està arrelat de manera molt particular a Nàpols, on

6 Aquesta citació i la següent provenen de <https://www.vesuviolive.it/cultura-napoletana/142179san-vincenzo-munacone-resuscitava-morti-fermo-colera-napoli/.>

REVISTA VALENCIANA DE FILOLOGIA / I I I (20I9) p. I27-I3 8

ANNA MARIA COMPAGNA

Seguint els passos de Sant Vicent Ferrer al Regne de Nàpols i Sicília / I 32 
San Vincenzo Ferreri è patrono insieme ad altri 51, di cui sette spagnoli, e patrono del Rione Sanità, conosciuto con l'appellativo di 'O Munacone. La sua statua è conservata nella Basilica di Santa Maria della Sanità (meglio conosciuta, appunto, come Chiesa di San Vincenzo alla Sanità), sita nel cuore del quartiere, dove atmosfera barocca e tradizione popolare si intrecciano e fondono per creare un perfetto connubio.

No és estrany, doncs, que a la tradició culta ${ }^{7}$ de les vides del sant, s'hi haja afegit la tradició l'oral, formalitzant-se després per praxi popular, que probablement apareix en la història un poc més tard, justament per la seua natura poc donada a deixar-nos testimoniances directes. És en el segle XIX quan a les testimoniances indirectes del culte s'hi afegeixen les directes, mitjançant construccions i/o monuments.

Grande affetto e gratitudine legano, ancora al giorno d'oggi, la comunità del quartiere al santo, dovuta alla grazia ricevuta durante l'epidemia di colera del XIX secolo. Secondo le credenze, nel 1836 la statua fu portata in processione in occasione dell'ennesima epidemia da cui venne sconvolta la città e, grazie all'intercessione del santo, il contagio terminò prodigiosamente. Da questo evento miracoloso, ogni 5 aprile, giorno della sua morte, dopo la funzione presso la chiesa, vi è il rito trase e jesce, dedicato al santo, in cui la statua del patrono viene portata in spalla dai membri delle associazioni cattoliche locali e, saltellando a ritmo, viene fatta entrare ed uscire per tre volte di seguito dall'entrata della chiesa. Una seconda celebrazione ha luogo durante il primo martedì di luglio, in ricorrenza del periodo in cui secondo la tradizione avvenne il miracolo: i bambini vestiti da fraticelli domenicani e le bambine da contadinelle

7 Per exemple és relativament recent la traducció del Tractat de la Vida Espiritual del sant <http:// www.invicchio.it/-dimorarivotorto/files/svincenzoferreri_trattato.pdf>. Com ja s'ha dit, però, també havien estat publicades altres obres com: Marchese, Domenico Maria (O.P.) (1634-1692) «Vita del glorioso apostolo delle Spagne S. Vincenzo Ferreri dell'Ordine de' Predicatori / composta dal M.R.P. ... Domenico Maria Marchese, in Napoli, per Geronimo Fasulo, 1669», i el suara esmentat Vicent Vitòria. «Vita, e miracoli dell'Apostolo Valenziano San Vincenzo Ferreri dell'Ordine de'Predicatori... / da Don Vincenzo Vittoria Valenziano, in Roma, per il Zenobj..., 1705».

REVISTA VALENCIANA DE FILOLOGIA / I I I (20I9) p. I 27-I38

ANNA MARIA COMPAGNA

Seguint els passos de Sant Vicent Ferrer al Regne de Nàpols i Sicília / I 33 
accompagnano la processione, terminata questa ritualità seguono festeggiamenti canori e pirotecnici. ${ }^{8}$

La festa tenia lloc entre dues dates: el 5 d'abril i el primer dimarts de juliol. El 5 d'abril es feia una processó amb una imatge del sant, mentre que el primer dimarts de juliol el barri es vestia de garlandes i lluminàries, amb la música de la banda i els focs artificials. En 1978 es decidí acabar amb la festa, en haver estat publicat d'un decret que imposava l'abolició de les celebracions públiques per motius religiosos. En 2001 es començà a discutir sobre una possible tornada de la festa, però les esperances foren decebudes per la Fiscalia de la República, que denuncià el risc d'infiltracions de la camorra. ${ }^{9}$

Heus ací, doncs, com s'explica que, més enllà de la imatge de la Sanità, són nombrosos «i contributi provenienti dall'arte figurativa presenti nella città di Napoli». Testimonien la fascinació que el sant ha suscitat no solament entre la plebs, sinó també entre els artistes, pintors, escultors i intel-lectuals que han transitat pel municipi partenopeu, com havia evidenciat el políptic de Colantonio, ja citat, i el bust d'argent del 1838, obra de Luigi Capozzi sobre un disseny de Camillo Guerra, per posar només algun exemple.

No sorprén, doncs, llegir que sant Vicent, 'o munacone ('el gran monjo', en napolità), ha suscitat

grande interesse in ogni strato sociale della popolazione napoletana e non, a partire dal XV secolo sino a giungere ai giorni nostri, dove ancora nelle reminiscenze delle tradizioni religiose è ben radicato il culto di questo santo dal carattere austero, come dimostrano le sue predicazioni e condanne feroci ai peccatori ed ai professanti diverse religioni, ma allo stesso tempo misericordioso e clemente, fautore di molteplici prodigi e miracoli. ${ }^{10}$

8 Vegeu: <https://www.vesuviolive.it/cultura-napoletana/142179-san-vincenzo-munacone-resuscitava-morti-fermo-colera-napoli/.>

9 La informació prové, ara i en les citacions del paràgraf següent, de <https://it.wikipedia.org/wiki/ Vincenzo_Ferreri\#Culto_di_san_Vincenzo_Ferreri_a_Gesualdo_(AV).>

10 Vegeu <https://www.vesuviolive.it/cultura-napoletana/142179-san-vincenzo-munacone-resuscitavamorti-fermo-colera-napoli/.

REVISTA VALENCIANA DE FILOLOGIA / III (20I9) p. I27-I38

ANNA MARIA COMPAGNA

Seguint els passos de Sant Vicent Ferrer al Regne de Nàpols i Sicília / I 34 
Tanmateix, el culte del sant traspassa els confins de la capital napolitana. A tota la regió de Campània es troba ben arrelat, ja siga a Gesualdo, a la província d'Avellino, com a Fisciano, a la província de Salern. A Gesualdo, els orígens són en part llegendaris. Es parla d'una comunitat religiosa siciliana que havia encarregat a un artista espanyol una imatge de sant Vicent i, durant el viatge envers Sicília, els portadors de l'estàtua feren una aturada a Gesualdo, on els habitants del lloc es van quedar la talla, encisats per la seua bellesa. Així doncs, el poble també s'apropia de la devoció per sant Vicent i la coordina amb la festa del Volo dell'Angelo, instituïda entre el 1833 i el 1876. Durant la festa

un bambino vestito da angelo viene aggrappato ad una fune di acciaio, tesa tra la torre nord-est del Castello e il campanile della chiesa del Rosario, e tirato, mediante l'ausilio di carrucole, lungo un tragitto di oltre 100 metri all'altezza di 25 metri sulla sottostante piazza Neviera. Da un palco montato a terra esce il diavolo, impersonato da un adulto. Inizia una disputa tra i due personaggi, in cui sono ripresi testi e scene delle sacre rappresentazioni medioevali. ${ }^{11}$

L'originalitat està justament a encertar a retornar-nos, en el nostre imaginari, aquelles representacions gràcies a les quals ha acabat per tenir una presència en l'escrit allò que ja apareix en les primeres testimoniances de les llengües romàniques. ${ }^{12}$

A Fisciano més tard,

nella Valle dell'Irno, ogni primo fine settimana del mese di agosto, San Vincenzo Ferreri viene festeggiato con una processione che si articola per le principali vie del paese. Fedeli provenienti da tutta la provincia seguono il passaggio della statua lignea del Santo domenicano, di San Bernardino da Siena (di cui Vincenzo Ferrer era amico) e di Sant'Antonio da Padova. Le tre statue sono conservate all'interno della chiesa di San Pietro.

11 Aquest text i el següent són provinents de <https://it.wikipedia.org/wiki/Vincenzo_Ferreri\#Culto_ di_san_Vincenzo_Ferreri_a_Gesualdo_(AV).>

12 Per exemple, vegeu la Seqüència de Santa Eulàlia, l'Auto de los Reyes Magos, etc.

REVISTA VALENCIANA DE FILOLOGIA / I I I (20I9) p. I27-I 38

ANNA MARIA COMPAGNA

Seguint els passos de Sant Vicent Ferrer al Regne de Nàpols i Sicília / I 35 


\section{Conclusions}

Com ja ha estat dit si ultrapassem les fronteres d'allò que fou el regne de Nàpols i de Sicília, malgrat el que poria pensar-se i era raonable creure, les coses no canvien massa. Ans al contrari: és el que pense que s'ha pogut evidenciar de les intervencions en aquest congrés per part d'Anna Maria Babbi i Chiara Concina. Començant amb la predel-la per la capella Griffoni a la basílica de Sant Petroni de Bolonya, datada al voltant del 1473, que representa els miracles del sant: es tracta d'una obra d'Ercole de' Roberti, ara a la Pinacoteca Vaticana. ${ }^{13}$ Pel que fa a la resta, si anem a consultar la veu relativa al sant de la Bibliotheca Sanctorum (1969: 1168-1176), llegim que entre el 1406 i el 1407 és difícil seguir el sant en els seus viatges apostòlics: «va e viene per il Nord Italia, il centro della Francia e la Spagna (soprattutto l'Andalusia)» (1969: 1171). Allò que no està demostrat és que passara pel centre i el sud d'Itàlia. Però, això fins a quin punt és significatiu?

De fet, a grans trets, no es pot compartir el que ha estat afirmat (i que s'ha reportat al començament de la nostra intervenció) per Serena Mascia, ${ }^{14}$ és a dir, que a Itàlia el culte del sant «è particolarmente sentito nel Sud dello Stivale». Si es fa una breu lectura al llistat de les 25 obres d'art que representen el sant a Itàlia en la Viquipèdia, ${ }^{15}$ s'hi veurà que les localitats citades estan distribuïdes de manera equànime per tot el territori italià i tenen unes motivacions més o menys anàlogues. ${ }^{16}$ Per no parlar de les quaranta localitats

$13<$ <ttps://it.wikipedia.org/wiki/Vincenzo_Ferreri\#Bibliografia>.

14 Vegeu la nota 6.

15 <https:/it.wikipedia.org/wiki/Vincenzo_Ferreri\#Bibliografia cit.>

16 Un exemple: a Turbigo, a la província de Milà, el culte a sant Vicent Ferrer es remunta al segle XVIII, amb l'arribada d'una relíquia «e con la processione delle campagne celebrata nel 1778, abbinando la devozione al santo alle antiche rogazioni del mese di maggio" (P. Mira 2013, Il dipinto san Vincenzo Ferreri di Baldassare Verazzi a Turbigo 2013 <http://www.antiqua.mi.it/A_Verazzi_Mira_mag2013. $\mathrm{htm}>$. El quadre és del 1850. Al web, s'hi pot llegir que «un San Vincenzo in gloria, affrescato da Lorenzo lotto tra il 1510 e il 1512-13, da tantissimi anni ospitato nella chiesa di San Domenico a Recanati, è stato da poco restaurato per la mostra Lorenzo Lotto nelle Marche alla Reggia di Venaria di Torino dal 9 marzo al 7». La notícia es remunta al 25 de gener del 2013. <https://www.cronachemaceratesi. it/2013/01/25/si-restaura-il-san-vincenzo-ferreri-in-gloria-di-lorenzo-lotto/284081/>.

REVISTA VALENCIANA DE FILOLOGIA / III (20I9) p. I27-I38

ANNA MARIA COMPAGNA

Seguint els passos de Sant Vicent Ferrer al Regne de Nàpols i Sicília / I 36 
(ciutats i pobles) italians on el sant és patró. ${ }^{17}$ Sorgeix el dubte que el sant siga vist com italià, o, almenys, que siga expressió d'allò que era, aleshores, la Corona d'Aragó.

\section{Bibliografia}

Bibliotheca Sanctorum XII, Roma, Istituto Giovanni XXIII, Pontificia Università Lateranense, 1969, pp. 1168-1176. Veu firmada per Sadoc M. Bertucci.

Alcalahí, B. de (1897) Diccionario biográfico de artistas valencianos. València, Federico Doménech.

Compagna, A. M. (ed.) (1990) Summa dei re di Napoli e Sicilia e dei re d'Aragona, Lupo de Spechio, Nàpols, Liguori, ( «Romanica Neapolitana», 26).

Escartí,V. J., (2018) «El record de la figura de sant Vicent, en els 600 anys de la seua mort», Afers XXXIII: 91/92 pp. 305-309 <https://editorialafers.blogspot.com/2018/11/ el-record-de-la-figur-de-sant-vicent.html>.

Ferrando, A., (2013) Sant Vicent Ferrer en la historiografia, la literatura, l'hagiografia $i$ l'espiritualitat al segle XV, València, Institució Alfons el Magnànim.

MirA, P., (2013) «Il dipinto san Vincenzo Ferreri di Baldassare Verazzi a Turbigo», <http:// www.antiqua.mi.it/A Verazzi Mira mag2013.htm>

Žıvкоvic, V., (2017) «San Vincenzo Ferrer. Qualche nota sul culto del predicatore domenicano apocalittico che salva dall'eresia e dalla peste», en G. Caprioti i C. Coltrinari, Crivelli Lotto Guercino. Immagini della predicazione tra Quattrocento e Settecento, Florència, Silvana Edidoriale, , pp. 47-57.

17 <https://it.wikipedia.org/wiki/Vincenzo_Ferreri\#Bibliografia cit>.

REVISTA VALENCIANA DE FILOLOGIA / I I I (20I9) p. I 27 -I 38

ANNA MARIA COMPAGNA

Seguint els passos de Sant Vicent Ferrer al Regne de Nàpols i Sicília / I 37 


\section{Apèndix I}

[Cap. 48 ${ }^{\circ}$ Qua è la costioni de chi devia esseri re de Aragona.

E sopre la questioni delli tre, czoè dell'infanto don Pedro Ferrando et dello conte d'Urgell et de Luise duca d'Anjou, se acordareno li regni: che intre de lloro fosse la pagi et non guerra, et che cessasseno omgnni opinione, et per Aragona fosseno posti tre homini docturi, per Valencia tre, et l'uno fo Sancto Vicienso dell'ordene de Sancto Dominico, per Catalonnya altri 3 , et cossì foreno novi; et quisti che stesseno nello castello de Casp et non ensesseno mai finiché avesseno delliberato et dechiarato chi devesse esseri re d'Aragona. Et visto che ebbero la questioni et la ragione de omgnniuno, dechiarareno che ll'infanto don Ferrando, figlio della sorella magiore dello re don Martino, ei più appresso allo morto, czioè allo re d'Aragona, et che devesse esseri re d'Aragona. Et cossì llo cridò da una finestra lo dicto sancto Vincenczo, dal castello de Casp, denante a omgnni homo de tucti li regni; et io lo sso bene per don Juhanne d'Ixar, lo antico et virtuuso patre del quali ogi hei medesmo Hohan d'Ixar, che fo allà presente; et per altri lo sso bene che ve foro. Et fo questa publicacione alla vigilia de Sancto Pietro et Sancto Paulo, alla fini dello mese de junnyo nell'anno 1411.

[Cap. $49^{\circ}$ ] Como Sancto Vincenso fo canoniczato.

E tal vidi diri al dicto don Juhanne d'Ixar al re don Alfonso dintro la chiesia de Santo Dominico in Napulli: che era refermata la ellecione del re don Ferrando, publicata per Sancto Vincenso, perché fo canoniczato per papa Calisto lo dì de Santo Petro e Santo Paulo; perqché si fosse estata injusta eleccione, non fora stato sancto Santo Vincenso, et Dio non averia concordato la eleccione et canoniczato en uno di Sancto Vincenso della festa de Sancto Petro e Sancto Paulo. Et questo parlamento fo quando venne la nova della canonicacione de sicto Sancto Vincenso al re Alfonso: el ditto re ne fe fare una sollenna processione per Napuli, per honore de Santo Vincenso, nell'anno 1455, venuta la nova de Roma, en quactro dì da po la dicta festa de Sancto Petro et Sancto Paulo.

REVISTA VALENCIANA DE FILOLOGIA / I I I (20I9) p. I27-I38

ANNA MARIA COMPAGNA

Seguint els passos de Sant Vicent Ferrer al Regne de Nàpols i Sicília / I 38 